\title{
Purposes of Audio-Visual Translation
}

\author{
Yan Chen \\ Feixian College \\ Linyi University \\ Feixian, Linyi, Shandong, China
}

\begin{abstract}
The highly-developed mass media give rise to growing exchange and contention in the audio-visual Culture between different countries, and studies on the audio-visual translation have thus acquired their greater significance. German functionalist translation theory maintains that all translating activities are determined by its general purpose. And this suggests it is extremely important to study the purpose of audio-visual translation under the context of globalization.
\end{abstract}

Keywords-audio-visual translation; globalization context; information content; aesthetic value; commercial value

\section{INTRODUCTION}

In a short one hundred years of history, film and television art has grown into a comprehensive and cosmopolitan art form with surprising speed and with its unique charm conquered the audience from all over the world. With the deepening of opening to the outside world, the exchange of China and other countries in politics, economy, culture and other various aspects of communication comes into a comprehensive and rapid development new stage. Cultural communication channels and forms both at home and abroad are more and more diversified. As a cosmopolitan and popular art form, film and TV undoubtedly occupies an important place in the communication. A large number of outstanding Chinese films go abroad. Through the film, so many foreign audiences are deeply attracted by five thousands of years of extensive and profound Chinese culture, and shocked by the magnificent eastern civilization. At the same time, along with the introduction of a large number of excellent foreign films, the Chinese audiences also enjoy the feast permeated with exotic culture. Mass of the film and television cultural exchange of the film and television translation put forward the major tasks and challenges. According to the German functional translation theory, any behavior (including translation) is a kind of purposeful activity. The film and television is a powerful medium in the context of globalization, as a result, film translation is considered to be a purposeful strong activity. This paper attempts to analyze the purpose of film translation activity starting from the characteristics of film translation and combining with the feature of era background.

\section{Film TRANSLATION ACTIVITIES UNDER THE CONTEXT OF GLOBALIZATION}

\section{A. Cultural Exchange and Cultural Fusion}

Economic globalization is the most important feature of human society in the 21 st century. Film and television as a powerful means of communication, plays an important role in the cultural exchange and dissemination of various nationalities. "With the communication becoming more advanced, the scale of the multinational film and television transmission is more and more big, ability is more and more strong, and the coverage is more and more widely. International communication of the film and television not only brought huge income for film and television industry, but also promote the international culture exchange. To a certain extent, the film and television compositions play a role in transmission of information, feeling expression and culture communication. It's just a bridge between different countries and nations in order to exchange international culture. As a matter of fact, film and television compositions enhance the communication between different ethnic groups and different culture." Language and culture are closely related. Language is the carrier of culture, and also a part of the culture inherent [2]. Cultural differences will refract to the corresponding language. The language translation problems will inevitably be involved during transforming the film and TV culture communication in different countries. Translation is the human society activities. As a medium and a form of language symbols, translation activities enable human beings to communicate their thoughts and feelings, transmit information and spread the culture. Any translation activities, therefore, is a conscious purposive behavior in certain situations. Under the context of globalization, film translation turns to be a powerful culture medium. In this way, the purpose of film translation is enhancing communication between the film and television art in different countries and promoting the spread and integration of film and TV culture in the world.

\section{B. Multicultural Coexistence and Competition with each other}

In the context of globalization, the different cultures of nationality and times lead to multicultural coexistence and competition with each other. However, "Globalization does not necessarily mean global convergence". In fact, "under the background of globalization, there is a fierce debate between the cultural localization or cultural globalization and cultural diversity or unified". With strong economic strength and 
advanced science and technology, Western developed countries, which has long been in the position of the cultural center and in the hands of the cultural output control, can make full use of this powerful tool of mass communication to instill the people in underdeveloped countries, such as the ideology of western values, ideas, even decadent lifestyle mandatorily.

\section{FILM TRANSLATION ACTIVITY MUST BE GUIDED BY THE AUDIENCE}

According to the German functional translation skopos theory, the purpose of the whole translation behavior decides the primary rule in any translation process. In order to complete the translation of film, you first need to understand the purpose of film translation. The author believes that the main purpose of the film translation includes the following three aspects.

\section{A. To be Correctly Convey the Information Content of TV and Movies}

Practitioner Nada said: "translation consists in the language of the person with the most natural and appropriate reappearance primitive information, first in terms of meaning and secondly in terms of style." What he said conclude the purpose of translation activities. As a branch of literary translation, film translation should also follow the rules. During the film translation, the words should not only deliver language information, but also effectively convey the cultural information. Different from general literature, film and television art is a combination of sound and painting art form, which also be called art of time and space. Synchrony is required during film dubbing due to the space-time restriction. Words for subtitle translation and the original discourse should be accomplished in roughly equal time in order to effectively transmit the information. The audience should also be considered with enough time to browse the subtitles. At the same time, movie translators should also take the audience into consideration during the process of subtitle translation. In fact, in order to correctly and effectively convey the raw information, sometimes we have to sacrifice a little fidelity .Take English movies translate into Chinese for example. As English and Chinese belong to different language families, when try to express the same meaning, the two statements length, number of words sometimes vary a lot. However, because of the limitation, translators should try to make the number of English words syllables and Chinese words equal in general.

For example:

Rossi: Down deep, the man is a lump of sugar. (Scent of a Woman)

\section{Translate as: 这个人好得很}

If we use literal translation for the underlined parts, the sentence will not fluent, and the number of words also will be increased.

Another example:

Stephanie: Have dinner with me tonight.
Michael: All right. And tomorrow night... and... Every night... For the rest of your life. (Love at First Sight)

丝黛芬尼:今晚陪我吃饭。

迈克尔: 好啊, 只要你愿意, 今生今世, 天天一块 吃。(《一见钟情》)

"For the rest of your life" translate into"今生今世 ", is natural and reasonable, at the same time also give full consideration to the juncture in the original language. At the same time, the cultural information transfer is one of the important purposes in TV and movies. In just a rich cultural information is passed to the target language audience effectively, make them and the raw audience have roughly equal cultural experience, namely obtain considerable cultural image.

As in the film "The Flashy Family," Zack once said: "Was Camille so lovely... even on her death bed?" If the name "Camille" literal translation into "卡米拉" in Chinese, the Chinese audience will seldom know she is a beauty in French writer Alexandre Dumas' novel The Lady with The Camillias .However, the translator translated into" 天上的仙 女", this form of translation not only effectively passed its cultural connotation, also left a good image in the minds of Chinese audiences.

\section{B. To Fully Embody the Aesthetic Value of TV and Movies}

Film is a comprehensive art combined with movies, music, painting, modeling, editing and other art forms. With its unique audio and visual impact and artistic appeal, film gives incomparable enjoyment to the audience. So the translation of the TV and movies should try to show the characteristics of TV and movies above. Translation is considered to be the art of language, which is one of the important elements in TV and movies. Therefore, to perfect show the aesthetic style of TV and movies, close scrutiny of translation language is indispensable. The main characteristics of translation language are colloquial, distinct, and instantaneous as well as comprehensive to match the picture action.

1) Simple, colloquial, popularized: Compared with literature genre such as novel and prose, the language of the $\mathrm{TV}$ and movies is concise and vivid, at the same time, easy to understand. It often turns in the form of a dialogue or inner monologue or narrator, which is very colloquial. Based on the distinct characteristics of film language, the translator have to take the language style of interpretation into consideration while translate the film. In that case, the foreign audience could fully feel the glamour of the interpretation of the language. Otherwise, the film will lose most of the audience for the target and artificial language.

For example:

Brock: This better be good. (Titanic)

Translate as: 布洛克: 不要是什么坏事。（《泰坦尼克 号》)

Gump: Stupid is as Stupid does. (Forrest Gump) 


\section{Translate as: 阿甘: 䖭人就做蚌事。(《阿甘正传》)}

2) Distinct: Film is the combination art of sound and image. Numerous vivid, lifelike, elegantly heartstrings images are performed by the actors. Actors in the film not only show the story in the performance, but also show the characters full of distinctive individuality. Thus, the film languages also show the unique personality of the characters in the film. In order to increase the character images, translator should strive to show the different personalities of the characters. If the translator overlook the diversity of different characters, and seldom change the style of language during translating, the characters in the film will become dull and lifeless. Thereby, image and the artistic charm of the film are significantly damaged by the same style of language translation.

For example:

Scarlett: As God as my witness... As God as my witness they're not going to lick me. I' $\mathrm{m}$ going to live through this and when it's all over, I'll never be hungry again. No, or any of my folk. If I have to lie, to steal, cheat, or kill, as God as my witness, I'll never be hungry again. (Gone with the Wind)

Translate into:

思嘉：让上帝做见证, 上帝做见证。我是不会屈服 的, 我要渡过这难关。战争结束后, 我再也不要挨饿 了。不要, 我的家人也不要。即使让我去撒谎, 去偷, 去骗, 去杀人, 上帝作证, 我也不要再挨饿。（《乱世 佳人》)

In this translation, Scarlett's raw characters are well reflected.

3) The instantaneity, without note: Dialogues in the film appear instantly and can't be repeatedly listened to (different from watching VCD or DVD) for the time for watching is limited. The audiences had to give up if they can not catch up the subtitle. Translation needs to match the following requirement: first, subtitles should neither too short nor too long; second, leave enough scanning time for the audience. It means that don't let the audience behind the subtitles. Different from other literature translation, the film translation cannot be refilled. So the translator should seek within a limited number of words to convey the language characteristics of TV and movies, which as far as possible concise, vivid and direct target language.

4) Comprehensive: Film is the combination art of voice and image. The combinations of film and television language and picture have a beneficial supplement to some extent for language $T V$ and movies. As in the film Forrest Gump, the principal pointed to the IQ distribution of Forrest Gump's mother and said: "Mrs. Gump. Now, this is normal. The Forrest is right here..." it translated into: "甘 夫人, 你看, 这个位置是正常的, 福勒斯特却在 这......” Cooperated with pictures, audience will know the word of "this" refers to Forrest Gump's IQ location.
Film and television art is a comprehensive art, which is also the art of language. To fully transmit the unique artistic style, the translator should know different language styles well in different films. Only the good translation of the dialogues in TV and movies can help the audience to appreciate the artistic charm of unique TV and movies, and further realize the aesthetic purpose of film translation.

\section{To Realize the Commercial Value of the Film}

As a mass art, film is considered to be a worldwide cultural entertainment from its origination. The final aim of the film producers is to earn box-office value maximally. As a result, the film and television translator in translation should consider the business purpose of TV and movies. In order to attract the attention of a wider audience, the translator should try to make the language more accessible and easier to understand. Of course, it not means that the translator can translate into any unconstrained and arbitrary style. In order to attract the audience attention, some translators often translate the title by hook or by crook. Such as film Mr. Doubt Fire translated into 《疑火太太》, what's more even translated into 《肥妈先生》 or 《窈苌奶爸》, translate The Matrix into 《二十二世纪杀人网络》 and so on to attract the audience.

\section{CONCLUSION}

Film translation activity tries to transmit the language and cultural information of the film. The purposes are to better achieve the aesthetic value and commercial value of $\mathrm{TV}$ and movies and maximize attract the viewers. In short, film translation activity aims to meet the needs of the audiences. At the same time, from a macro point of view, the purpose is to promote cultural exchanges between the different languages and different ethnic groups.

\section{REFERENCES}

[1] Christiane Nord. Translating as a Purposeful Activity: Functionalist Approaches Explained [M]. Shanghai: Shanghai Foreign Language Education Press, 2001.23-27.

[2] Eugene A Nida, Charles Taber. The Theory and Practice of Translation [M]. Shanghai: Shanghai Foreign Language Education Press, 2004.12.

[3] Peng Jixiang. The Chinese National Film and Television Art under The Context of Globalization [A]. Beijing: Beijing Broadcasting Institute Press, 2004.

[4] Qian Shaochang. Film Translation---More and More Important in Translation Field [J]. Chinese Translators Journal, 2000, (1).

[5] Zhou Chan. English Classic Movie Script Assembled [M]. Guangzhou: Guangdong Economic Press, 2001.

[6] Zhang Chunbai. Film Translation Study [J]. Chinese Translators Journal, 1998, (2).

[7] Bi Wencheng. The Particularity of Film Language Translation [J]. Journal of Ningbo Institute of Education, 2003, (5).

[8] Zhang Kerong. Translators' Subjectivity And The Translation of Film Title [J]. Journal of Social Science in Guizhou, 2003, (6). 